\title{
O discurso curricular intercultural na educação de jovens e adultos e a produção de subjetividades
}

\author{
Rosângela Tenório de Carvalho \\ Universidade Federal de Pernambuco
}

\section{Resumo}

0 discurso pela interculturalidade, ao contrapor-se às formas homogeneizadoras de diferentes processos educativos, apresenta uma vontade de poder-saber e problematiza experiências dominantes de currículos monoculturalistas, ao mesmo tempo em que produz subjetividades multidimensionais de classe, gênero, raça, etnia, geração. Sob o enfoque da análise foucaultiana do discurso, desenvolveu-se um estudo sobre o eixo pedagógico e as regras de normalização da formação discursiva da interculturalidade no campo da educação de jovens e adultos, com vistas a analisar os enunciados que conformam o sujeito da interculturalidade. Para tal análise, foram selecionados, no discurso pela interculturalidade, enunciados que delineiam modos de abordar as práticas de objetivação do ser jovem e adulto na sociedade e em relação a si próprio, isto é, enunciados que indicam processos de governamentalidade - técnicas de si - dos sujeitos da educação. Examinou-se o jogo de poder-saber subjacente às verdades apresentadas no discurso pela interculturalidade, as quais afırmam o cidadão coletivo e/ou multicultural. Em relação à produção de subjetividades no discurso curricular, pode-se considerar, a partir de uma perspectiva nietzscheana, que, ao dizer-se da interculturalidade em substituição à homogeneização cultural, diz-se também daquilo que se é.

\section{Palavras-chave}

Discurso - Subjetividade - Interculturalidade - Técnicas de si Educação de jovens e adultos. 


\title{
The intercultural curriculum discourse in the education of youngsters and adults and the production of subjectivities
}

Rosângela Tenório de Carvalho

Federal University of Pernambuco

\begin{abstract}
The discourse for interculturality, by going against the homogenizing forms of different education processes, describes a will to powerknowledge and problematizes dominant experiences of monoculturalist curricula, whilst producing multidimensional subjectivities of class, gender, race, ethnicity, and generation. Under the approach of the Foucauldian analysis of discourse, a study was developed here of the pedagogical line and rules of normatizing of the discursive formation of interculturality in the field of the education of youngsters and adults, with a view to analyze the statements that shape the subject of interculturality. For such analysis, statements were selected from within the discourse of interculturality which outline manners of dealing with the practices of objectivation of youngsters and adults towards society and towards themselves, that is, statements that indicate processes of governmentality - techniques of the self - of the subjects of education. The study examined the play of power-knowledge underlying the truths presented in the discourse of interculturality, which affirm the collective and/or multicultural citizen. With respect to the conduction of subjectivities in the curriculum discourse, it can be considered, from a Nietzschean perspective, that when speaking about interculturality replacing cultural homogenizing, one is also speaking about what one is.
\end{abstract}

\section{Keywords}

Discourse - Subjectivity - Interculturality - Techniques of the self Education of youngsters and adults.

Contact:

Rosângela Tenório de Carvalho rosangelatc@gmail.com 
Estudos no campo da pedagogia sobre a relação entre currículo, cultura e subjetividade (CORAZZA, 1997, 2001; SILVA, 2000; COSTA, 2001, 2004; CARVALHO, 2004, 2009, 2010) têm-nos deixados atentos/as à problemática da produção de subjetividades multidimensionais.

0 currículo, no sentido como aqui o entendemos, é um dispositivo disciplinar em que se desenvolve um discurso pedagógico engendrado em contextos diversos, os quais, por sua vez, envolvem atores sociais implicados em procedimentos de controle, seleção, organização e redistribuição. Trata-se de discursos que se dão em uma intertextualidade de versões estéticas, políticas, religiosas e disciplinares; discursos em disputa, uma vez que cada grupo social procura fazer valer seus significados próprios em detrimento dos significados de outros grupos (SILVA, 2000).

De acordo com a arqueologia de Michel Foucault, a prática discursiva reflete um conjunto de

regras anónimas, históricas, sempre determinadas no tempo e no espaço, que definiram, numa dada época e para uma determinada área social, económica geográfica ou linguística, as condições de exercício da função enunciativa. (FOUCAULT apud CORDEIRO, 1995, p. 176)

Partindo de tal argumento e da teoria póscolonialista sobre os efeitos das práticas coloniais e neocoloniais na produção de subjetividades multidimensionais, interessa-nos analisar, no campo curricular, os processos discursivos que dizem o que é e o que deve ser a educação.

Esse mapa que temos perseguido em nossas análises tem-nos permitido refletir sobre alguns pontos: o tratamento da linguagem como um sistema de significação; a identificação do poder como uma rede produtiva; o desenvolvimento de um olhar que combina aspectos da dominação e da resistência nas diversas práticas sociais e culturais; o reconhecimento do saber como uma relação de força; e o acolhimento do discurso pedagógico como prática que obedece a regras, e, tal como um testemunho histórico, descrevese a si próprio e às suas articulações, constrói e posiciona os sujeitos (CARVALHO, 2004).

$\mathrm{Na}$ intenção de apresentar os argumentos que sustentam nosso posicionamento sobre a relação entre currículo, discurso e subjetividades multidimensionais, pretendemos, neste texto, percorrer um breve caminho que apresente: i) um mapa teórico sobre as concepções de discurso, poder e subjetividade na perspectiva pós-colonialista; ii) uma análise dos processos de subjetivação do sujeito da educação de jovens e adultos na perspectiva intercultural, enfatizando o eixo pedagógico desse discurso e a regra de normatização do sujeito da interculturalidade; iii) nossas considerações finais.

\section{Discurso, poder e subjetividade}

0 conceito de discurso em Foucault remete a práticas que formam sistematicamente os objetos de que falam e constroem efeitos de verdade. "Assim o discurso define, constrói e posiciona os sujeitos humanos" (GUARESCHI, 1997, p. 174).

Ao tratar de tal concepção, Foucault articula outros conceitos, como o de poder. Este, por sua vez, encontra-se imbricado com os conceitos de saber e de subjetividade. No que concerne aos saberes, o autor concebe-os como formas de relações de forças, formas de poder. 0 poder é entendido como uma relação; é móvel, fluido, capilar e está em toda parte (SILVA, 2000). Para Foucault (1996), não existe saber que não seja expressão da vontade de poder. Ao mesmo tempo, não existe poder que não se utilize do saber, sobretudo de um saber que se expressa como conhecimento das populações e dos indivíduos submetidos ao poder. Afırma o autor:

Temos antes que admitir que o poder produz saber (e não simplesmente favorecendo-o porque o serve ou aplicando-o porque é útil); que poder e saber estão diretamente implicados; que não há relação de poder 
sem constituição correlata de um campo de saber, nem saber que não suponha $\mathrm{e}$ não constitua ao mesmo tempo relações de poder. [...] Resumindo, não é a atividade do sujeito do conhecimento que produziria um saber, útil ou arredio ao poder, mas o poder-saber, os processos e as lutas que o atravessam e que o constituem, que determinam as formas e os campos possíveis do conhecimento. (p. 30)

Nessa perspectiva, é possível dizer que as relações de poder são imanentes à educação e aos seus discursos (DEACON; PARKER, 1994), não havendo, portanto, como escapar do poder, que pode ser visto em sua positividade, no sentido de que é também expressão de luta e de resistência, tal como está realçado no discurso foucaultiano. Em suas análises, Foucault (2000) ressalta as relações de poder como uma das categorias essenciais no estudo sobre os processos de subjetivação do sujeito.

Quando se fala de subjetividade na perspectiva foucaultiana, fala-se em modos de subjetivação (FISCHER, 1999). Assim, a proposição de Foucault refere-se ao modo como "o sujeito faz a experiência de si mesmo em um jogo de verdade no qual está em relação consigo mesmo" (p. 42).

Foucault estudou a hermenêutica das técnicas de si na prática pagã e na prática cristã dos primeiros tempos. Seu objetivo nos estudos que desenvolveu sobre as técnicas de si foi:

Esboçar uma história das diferentes maneiras nas quais os homens, em nossa cultura, elaboram um saber sobre eles mesmos: a economia, a biologia, a psiquiatria, a medicina, a criminologia. 0 essencial não é tomar esse saber e nele acreditar piamente, mas analisar essas pretensas ciências como outros tantos 'jogos de verdade', que são colocados como técnicas específicas das quais os homens se utilizam para compreenderam aquilo que são. (FOUCAULT, 1994, p. 2)
Em seus estudos, Foucault (2004) enfatiza três técnicas de si definidas pela filosofia estoica: as cartas aos amigos e o que elas revelam de si; o exame de si mesmo e de sua consciência, que compreende a avaliação daquilo que foi feito, daquilo que deveria ter sido feito, e a comparação dos dois; e, finalmente, a askesis, um ato de rememoração. "0 objetivo dessas técnicas é a subjetivação da verdade”, observa Foucault (2004, p. 12). Sobre a askesis, o autor afirma:

Longe de indicar a renúncia a si mesmo, implica na consideração progressiva de si, a maestria de si - uma maestria à qual se alcança não pela renúncia à realidade, mas ao se obter e assimilar a verdade. 0 objetivo final da askesis não é preparar o indivíduo para outra realidade, mas de lhe permitir acessar a realidade deste mundo. [...] A askesis é um conjunto de práticas pelas quais o indivíduo pode obter e assimilar a verdade, e transformá-la em um princípio de ação permanente. A alêheia se torna o êthos. É um processo de intensificação da subjetividade. (p. 13)

De acordo com ele, desde o século XVIII até a época atual, as ciências humanas (inclusive a pedagogia) reinseriram as técnicas de verbalização em um contexto diferente, fazendo delas não o instrumento de renúncia do sujeito a si mesmo, mas o instrumento positivo de constituição de um novo sujeito. "Que a utilização dessas técnicas deixou de implicar a renúncia do sujeito a si mesmo constitui uma ruptura decisiva" (FOUCAULT, 2004, p. 21).

Para Foucault (2000), é preciso, pois,

analisar as racionalidades específicas mais do que invocar sem fim os progressos da racionalização em geral. [...] é necessário remontar a processos muito mais longínquos se queremos compreender através de que mecanismos nós nos encontramos prisioneiros da nossa própria história. [...] 
este novo modo de investigação consiste em tomar as formas de resistência dos diferentes tipos de poder como ponto de partida. Ou, para utilizar outra metáfora, consiste em utilizar esta resistência como um catalisador químico que permita colocar em evidência as relações de poder, de ver onde elas se inscrevem, de descobrir os seus pontos de aplicação e os métodos que utilizam. (p. 101)

Em suas análises sobre a história da organização do saber, em particular quando estudou a loucura, Foucault desenvolveu, ainda, o conceito de governamentalidade. Esta seria o encontro entre as técnicas de poder, que estão a determinar a conduta dos indivíduos, e as técnicas de si, que permitem aos indivíduos efetuarem, eles mesmos ou com a ajuda dos outros, operações sobre seus modos de ser.

\section{Perspectiva pós-colonialista}

A perspectiva pós-colonial, segundo Peter McLaren (1993), emerge num contexto em que a organização social das lutas discursivas privilegia novas formas de dominar; ela surge, portanto, como um espaço para "novas liberdades e recriações de relações de poder” (p. 14).

Grande parte dos estudos desenvolvidos a partir de tal perspectiva está voltada para o campo literário, para a análise de obras escritas do ponto de vista dos dominadores (análise das narrativas que constroem o Outro colonial como objeto de conhecimento e sujeito subalterno) e de obras escritas por pessoas pertencentes aos grupos colonizados (análise das narrativas de resistência ao olhar e ao poder imperial). Os trabalhos de Frantz Fanon (1975) são exemplos relevantes no campo da pesquisa pós-colonial e têm sido referência para diversos estudos. A importância de seus trabalhos é confirmada, inclusive, pelo fato de serem mencionados em dois textos de referência no campo do póscolonialismo: o estudo de Paulo Freire nos anos 1970 (Pedagogia do oprimido), que cita o texto de Fanon intitulado Los condenados da tierra; e o estudo de Homi Bhabha nos anos 2000 ( $O$ local da cultura), que discute e analisa o texto Pele negra, máscaras brancas, também de Fanon.

A perspectiva pós-colonial permite-nos reforçar a importância de análises que conjuguem os aspectos da dominação e da resistência. Nesse sentido, corroboramos os argumentos de Tomaz Tadeu da Silva (2000) quando ele afirma que é tarefa da perspectiva pós-colonial estar atenta, por exemplo, a formas aparentemente benignas de representação do Outro nos diversos currículos contemporâneos, particularmente as formas superficialmente vistas como multiculturais, nas quais o Outro é visitado de uma perspectiva do turista ${ }^{1}$, "a qual estimula uma abordagem superficial e voyerista das culturas alheias" (p. 134). Trata-se, conforme observa Carlinda Leite (2002), de

um tipo de currículo que trabalha esporadicamente e de forma fragmentada temas da diversidade cultural, [...] promovendo um olhar do 'diferente' como algo de estranho e exótico. (p. 143)

Essa formulação desenvolvida por Silva (2000) e por Leite (2002) encontra ressonância na abordagem freireana de educação e nas abordagens pós-modernas e pós-estruturalistas em sua influência no campo da teoria póscolonialista do currículo.

Freire (1997) enfatiza a dimensão múltipla da interculturalidade, e, nesse sentido, ressalta que "as diferenças interculturais existem e apresentam cortes: de classe, de raça, de gênero e, como alongamento destes, de nações" (p. 31); ele nos alerta, ainda, para o fato de que "essas diferenças geram ideologias, de um lado, discriminatórias, de outro, de resistência” (p. 31).

Santiago Castro-Gómez (2003), em seu estudo sobre a invenção do outro, defende que esta não se refere apenas às formas como os grupos representam-se, mas fundamentalmente

1 - Sobre 0 olhar turista, ver 0 que Torsten Husén (1988) designa por currículo turístico. 
aos dispositivos de poder-saber a partir dos quais essas representações são construídas. 0 autor parte do discurso de Beatriz González para dizer sobre as práticas disciplinares que forjaram os cidadãos latino-americanos do século XIX - as constituições, os manuais de urbanidade e as gramáticas da língua - e afirmar que as tecnologias de subjetivação possuem um denominador comum: "su legitimidad descansa en la escritura” (p. 148). Se considerarmos que nossa sociedade configura-se sob o comando dos escritos sociais, o texto escrito toma força e relevância nas análises sobre subjetividades multidimensionais.

La palavra escrita construye leys e identidades nacionales, diseña programas modernizadores, organiza la comprensión del mundo en terminós de inclusiones y exclusiones. (p. 149)

Assim afirma Castro-Gómez (2003), justificando a subjetividade moderna que, em sua opinião, tem na pedagogia seu grande artífice e sua materialização. Diz ele, ainda, que a escola constitui um espaço onde se forma o sujeito que os ideais regulativos da constituição reclamam.

Em acordo com os autores mencionados, pode-se afirmar que a teoria pós-colonial tem sido fundamental nos estudos sobre os efeitos e as práticas coloniais e neocoloniais na produção de subjetividades multidimensionais. Embora reconheçamos que a epistemologia da colonização sofreu transformações significativas, condicionadas por processos sociais, políticos, econômicos e culturais dos séculos mais atuais, em particular a partir do século XIX, com a consolidação dos dispositivos da sociedade disciplinar - como as ciências e a escola -, podemos dizer que há uma epistemologia colonial que se mantém em sua regularidade enunciativa, isto é, que está presente no campo educacional, no âmbito das relações entre saberes, nas formas de inferiorização dos emigrados do campo para a cidade, das mulheres, dos homens e mulheres de cor, dos homens e mulheres em suas orientações sexuais diferentes do que está autorizado como normal, dos povos indígenas. Ou seja, o fato de o discurso educacional contemporâneo estar, ainda, moldado pela herança epistemológica da colonização coincide com o discurso moderno, quando este afirma e reafirma a primazia de um conhecimento universal firmado na concepção eurocêntrica ou norte-americana.

Chamamos a atenção, portanto, para processos de subjetivação implicados no discurso pedagógico pela interculturalidade e nas regras de normatização desse discurso. 0 sujeito da interculturalidade é aqui entendido como o sujeito produzido no âmbito da formação discursiva da interculturalidade; tal formação diz e atua sobre a forma de os indivíduos serem, sobre como eles podem e devem comportar-se na escola ou em outros espaços sociais, sobre como deve ser o sujeito coletivo - um cidadão multicultural (CARVALHO, 2004).

Elegem-se como espaços institucionais onde se forma o conjunto discursivo em favor da interculturalidade aqueles lugares cujos enunciados parecem mais significativos, seja por fazerem parte da rede social que tem o desejo e o poder de enunciação e, portanto, de produzir efeitos de vontade de verdade no campo educativo, seja pela singularidade e pluralidade de suas ações, as quais, mesmo diferenciadas, compartilham e relacionam-se com as mesmas regras de governo.

Apresentamos, assim, uma análise a partir de enunciados do Consejo de Educación de Adultos de América Latina (CEAAL); do Movimento dos Trabalhadores Sem Terra (MST); da United Nations Educational, Scientific and Cultural Organization (UNESCO); do Ministério da Educação (MEC), do Conselho Nacional de Educação (CNE) e da Associação Nacional de Pós-Graduação e Pesquisa em Educação (Anped), por meio dos Grupos de Trabalho (GTs) sobre Movimentos Sociais e Educação, Currículo, Educação Popular e Educação de Jovens e Adultos. 


\section{Processos de subjetivação do sujeito da educação de jovens e adultos na perspectiva intercultural: eixo pedagógico}

Trata-se, nesta seção, da identificação do eixo pedagógico que governa os discursos pela interculturalidade no campo curricular da educação de jovens e adultos (EJA); trata-se, em outras palavras, de um enfoque nos arranjos discursivos de poder-saber presentes na ordem interna desses discursos e atuantes na produção do sujeito da interculturalidade.

0 que denominamos como eixo pedagógico do discurso pela interculturalidade no campo curricular da EJA está anunciado pelas racionalidades sociopolítica e epistemológica que afırmam a educação intercultural - na perspectiva da democratização dos direitos humanos e das relações entre os diferentes saberes - e o acesso ao conhecimento como elementos de humanização do humano. Tais racionalidades implícitas nos enunciados das regiões discursivas analisadas em nosso trabalho sustentam a prescrição dialógica entre culturas e a constituição de um sujeito cidadão multicultural no currículo brasileiro de EJA.

0 discurso pedagógico pela interculturalidade está condicionado a processos de ressignificação de enunciados, distribuição de modos de enunciação, negociação de formas de expressão da multiculturalidade, afiliação e normalização de identidades, processos estes que funcionam a partir das regras de governo do discurso pela interculturalidade no campo curricular da EJA, regras estas que incidem nos processos de convergência dialógica entre culturas diversas.

Entendemos que o discurso intercultural, ao tornar-se objeto de conhecimento escolar, ou seja, ao tornar-se um texto pedagógico, passa a ter como função discursiva a prática de controle, transformação e reprodução dos discursos e do poder (DIÁZ, 1990). Nesse sentido, dizemos que os processos de convergência entre culturas são relações dialógicas permeadas por poder, o que significa dizer que o sujeito da educação, no âmbito dessas relações, é constituído por operações de poder.

Ao tratarmos do eixo pedagógico do discurso pela interculturalidade no campo curricular da EJA, focalizaremos os enunciados de normalização do sujeito cidadão multicultural nas referidas regiões discursivas. Substantivamente, pretendemos descrevê-los e analisá-los em suas formulações a respeito do sujeito da educação intercultural.

Ao analisarmos tais enunciados, nossa intenção está condicionada não simplesmente ao que eles dizem, mas ao que nos levam a pensar sobre o processo de construção de uma pedagogia na perspectiva da interculturalidade. Do que está afirmado, inferimos que, nas regiões discursivas do campo curricular da EJA no Brasil, esse processo de construção de uma pedagogia na perspectiva intercultural está associado à pedagogia do diálogo desenvolvida por Paulo Freire. Essa pedagogia dialógica nas regiões discursivas que a ela estão afiliadas é entendida tal como foi tratada no livro Pedagogia do oprimido, em que Freire propõe uma abordagem dialógica. Com efeito, trata-se de uma concepção que, tendo como objetivo o diálogo entre culturas, é uma referência para a construção da pedagogia intercultural, mesmo para as vertentes que estão a defender tal perspectiva a partir de um lugar teórico que não compactua com a centralidade do sujeito ou com o entendimento de que o conhecimento constitui uma possibilidade para a libertação dos processos de opressão social e cultural. Tal abordagem dialógica, entretanto, é referência principalmente para uma discussão no campo da educação intercultural que contemple as tramas históricas do poder e sua incidência no campo educacional, como é o caso de posicionamentos no seio da região discursiva acadêmico-educacional, em particular, no GT de currículo ao qual nos associamos.

O lugar teórico a que nos afiliamos - a pedagogia freireana -, para além do que já dissemos, é entendido também como um disposi- 
tivo pedagógico, isto é, como uma rede que envolve diferentes elementos, tais como discursos, instituições, organizações arquitetônicas, leis, regulamentos, enunciados científicos, proposições filosóficas e morais (MARTON, 1985), e que, como todo dispositivo, está associado à produção de verdade e atua como um poder não repressivo; mais ainda, como um dispositivo de produção de subjetividades. Nesse sentido, interessa-nos problematizar, no que diz respeito ao sujeito da educação intercultural, a vontade de verdade expressa nessa pedagogia em construção, associada à pedagogia freireana e a outros domínios discursivos. Não pretendemos analisar se se trata de algo bom ou ruim, pois entendemos ser preciso romper com o maniqueísmo do bem e do mal, das verdades universais, e aproximarmo-nos da historicidade do conhecimento, da análise das relações de poder (FOUCAULT, 1995; VEIGA-NETO, 1998).

Como todo o processo educativo, a formação discursiva da interculturalidade diz e atua sobre a forma de ser dos indivíduos, ou seja, orienta como eles podem e devem comportar-se na escola ou em outros espaços sociais. Essa orientação aponta para o sujeito coletivo como um cidadão multicultural (alunos, alunas, educadores, educadoras) e delimita seus valores. Ela indica como, por meio da educação humanizante intercultural, deve-se confrontar uma sociedade globalizada, povoada por miséria, desigualdades, corrupção e injustiças. Diante de tal sociedade perdida, o objetivo é incidir sobre os sujeitos da educação e, por meio do governo dos cidadãos, governar melhor os destinos da sociedade globalizada, agora numa perspectiva humanizadora.

Nos enunciados analisados, é visível essa intencionalidade de instituição de novas identidades que possam viabilizar sociedades mais justas, nomeadamente quando, na região discursiva dos movimentos sociais, assume-se como referência a educação popular em seu posicionamento em favor al cultivo de esas identidades movilizadoras y afirmadoras de la dignidad de las personas y de la legitimidad de las luchas por hacer valer sus derechos. (CEAAL, 2000, p. 9)

Ou quando se afirma a autonomia dos sujeitos, a construção de indivíduos solidários:

El incremento de los procesos de anomia y desencanto social coloca a la educación popular el reto de reforzar su aporte a la construcción de identidades, de referencias comunes para la acción colectiva, de cultivo de la memoria histórica, de afirmación de los lazos de solidaridad. Todo esto en la perspectiva política de afirmar sujetos autónomos que hagan valer su palabra y visión en el entramado de la sociedad civil y de los procesos de democratización. (p. 9)

Esse parece ser um momento de romper com o cidadão instituído sob a égide do pensamento moderno iluminista e sob o lastro do sujeito-cidadão do Estado-nação, agora substituído pela sociedade civil.

En este panorama latino americano de principios del tercer milenio occidental el concepto de la sociedad civil aparece como un detonante de reflexiones encaminadas a clarificar el tema del sujeto del cambio social y la fuente de energías culturales para impulsarlo. (p. 9)

Hablar entonces de la emergencia de la sociedad civil, más allá del debate sobre la categoría conceptual, nos remite a un discurso que busca ordenar las nuevas coordenadas de una nueva civilización y de nuevas lógicas de civilidad sustentadas en la inclusión el cultivo de la diversidad y por la afirmación de la equidad. El sujeto de esta nueva civilización y civilidad es, en términos genérico, la sociedad civil y en términos individuales y organizativos la ciudadanía. (p. 10) 
Justifica-se uma cidadania com referência à sociedade civil como uma possibilidade de reconhecimento da diversidade cultural.

A idea de la sociedad civil nos remite también de una gran variedad de voces y rostros, de temáticas y de campos de acción, de formas de asociación y de expresión pública. A una multiplicidad de sujetos. El reto, además del respeto a la diversidad y del cultivo de la pluralidad es ir encontrando las causas comunes y los mínimos de una ética privada y pública. (p. 10)

O discurso do MST está conformado a uma afırmação identitária sob os auspícios dos movimentos sociais e de certa vontade de mostrar a cara pela negação de um conceito de identidade do cidadão com direitos e deveres. Assume uma cidadania firmada nas lutas sociais, com base em um cidadão que, por suas lutas, deve ser um cidadão respeitado. Parecenos tratar-se de uma forma diferente de se conceber o cidadão.

Sem Terra tornou-se nome próprio. Nome de trabalhadores organizados lutando pela Reforma Agrária e para transformar a sociedade. [...] Sem Terra tornou-se sinal do resgate da dignidade de trabalhadores e trabalhadoras chamados vagabundos, chutados de um canto para outro. Conquistou, pela sua opção de entrar na luta, uma identidade: sou Sem Terra. Tornou-se, por causa do MST, um cidadão respeitado. E o MST nada mais é do que centenas de milhares de Sem Terra. (MST, 1996, p. 5)

Podemos dizer que entram em cena novos atores sociais, de acordo com Eder Sader (1988), e novas cidadanias, as quais são explicadas a seguir:

O contrato social, tal como a modernidade o desenvolveu, fundava-se na cidadania delimitada através do estado-nação. Este era a arquitectura política que garantia aos indivíduos e aos grupos um conjunto de deveres e protecções sociais e políticas em troca da sua desistência das identidades a nível local. Isto é, a sua lealdade já não se baseava em pertenças étnicas, familiares, religiosas e outras teias da tradição, mas naquilo que se assumia como sendo algo comum, como a cultura nacional, o território, a língua, etc. (STOER; MAGALHÃES, 2003, p. 1)

De certa forma, estaríamos falando do que Stephen Stoer e António Magalhães (2003) nomearam de rebelião das diferenças, em referência a grupos e indivíduos que durante muito tempo estiveram subordinados às formas de subjetivação fundadas no Estado-nação e que passam a assumir-se como alteridade, configurando um processo de resistência às formas consolidadas por esse Estado. Em nosso olhar, os diferentes movimentos sociais têm representado bem essa rebelião das diferenças, o que está em consonância com os estudos póscoloniais de Bhabha (2000) no que diz respeito ao hibrido, aquele que carrega em si as marcas do poder e também as marcas de resistência. No discurso dos movimentos sociais, está presente essa narrativa da resistência, o que hoje reconhecemos como opressão póscolonial advinda do impacto das relações de poder entre as nações e das relações de poder instituídas no âmbito local, dentre as quais a educação é uma vertente.

Os enunciados da região discursiva da transnacionalização da educação referem-se, ainda, à construção do sujeito coletivo, com destaque para a especificidade de gênero. Ao se defender a autonomia da mulher e a igualdade entre gêneros mediante a educação de adultos, pretende-se fazê-lo

educando el hombre y la mujer de modo que se compartan mejor las múltiples tareas y responsabilidades"; e também "aletando a la mujer a organizarse para 
promover una identidad colectiva y crear organizaciones femeninas que fomenten el cambio. (UNESCO, 1997, p. 312)

Embora as questões de gênero estejam presentes nos enunciados da região discursiva da política educacional, há uma ênfase na instituição de uma identidade de cidadão condicionada à superação das discriminações culturais em relação à idade.

A superação da discriminação de idade diante dos itinerários escolares é uma possibilidade para que a EJA mostre plenamente seu potencial de educação permanente relativa ao desenvolvimento da pessoa humana face à ética, à estética, à constituição de identidade, de si e do outro ao direito ao saber. (BRASIL, 2000, p. 149)

A educação de jovens e adultos é, pois, vista como uma possibilidade

de abertura para o mundo contemporâneo em seus desafios e exigências mais urgentes e um dos meios de reconhecimento de si como sujeito e do outro como igual. (p. 149)

Ela aponta a inserção dos indivíduos nos processos educacionais como condição para a construção da identidade de cidadão. De certa maneira, trata-se ainda de uma visão de construção de identidades sob o governo do discurso do Estado-nação, diferentemente da perspectiva dos movimentos sociais, tal como apresentamos.

$\mathrm{Na}$ região discursiva acadêmicoeducacional, há uma afiliação a teorias que veem os processos de construção identitária e reconhecem a pluralidade e a necessidade de formação de docentes para a pluralidade cultural por meio de estágios supervisionados e de um trabalho com teorias desenvolvidas em diferentes campos de saber (CANEN, 1999). Indicam-se os “aportes pós-modernos, particularmente pós-colonialistas" como justificativa para que "a constituição dessas identidades propriamente ditas" (p. 5) seja objeto de atenção. Defınem-se

quatro dimensões [...] na análise da categoria identidade: seu caráter de construção, sua hibridização, sua relação com a diferença e sua representação em práticas educacionais. (p. 5)

Do ponto de vista das práticas pedagógicas nomeadas por Foucault (1994) como técnicas de subjetivação, observamos nos enunciados a estratégia identitária das histórias de vida, seja por meio de histórias pessoais, seja mediante histórias que falem de costumes, artes de ser e de viver de antepassados. Essas histórias de vida são justificadas na perspectiva de uma reconstituição da autoestima dos indivíduos envolvidos na educação de jovens e adultos. Diz-se:

a recuperação da auto-estima, da identidade pessoal e cultural e o reconhecimento mútuo dos educandos envolve a rememoração de suas histórias de vida, de seus projetos e expectativas. (RIBEIR0, 2001, p. 174)

Tal estratégia é justificada, ainda, como uma forma de valorização das tradições culturais:

na recuperação das histórias de vida dos alunos, tem papel importante a valorização das tradições culturais e do saber prático que os educandos detêm. (p. 174)

\section{Técnicas de subjetivação}

As histórias de vida funcionam, assim, como ferramenta significativa para viabilizar o projeto de uma educação na perspectiva intercultural na educação de jovens e adultos. Elas também podem ser vistas de outra forma, pois, ao dizer de si mesmo, tal como ao falar verdades de si sobre sua sexualidade, seus pecados, seus saberes, suas formas de ser, o in- 
divíduo, em diferentes centros/locais de poder (a aula, por exemplo), torna-se um objeto de saber para si próprio e para os outros (o psicólogo, o padre, o professor, o coordenador), isto é, torna-se objeto de conhecimento. Como esse é um processo discursivo definido por quem propõe o recurso à estratégia de histórias de vida, embora esta seja geralmente justificada numa perspectiva de emancipar o indivíduo, trata-se também de um processo regulador, ou, nas palavras de James Marshall (1994), de um processo controlador. Para o autor, "a chave para a tecnologia do eu supõe a possibilidade de dizer-se a verdade sobre si próprio” (p. 126).

Para além das narrativas de vida, há uma gramática voltada para as situações de recuperação de autoestima, autoimagem, autonomia e de relação direta com a construção da identidade.

A imagem que os educandos têm da escola tem muito a ver com a imagem que têm de si mesmos dentro dela. Experiências passadas de fracasso e exclusão normalmente produzem nos jovens e adultos uma auto-imagem negativa. (RIBEIRO, 2001, p. 43)

É especialmente importante, no trabalho com jovens e adultos, favorecer a autonomia dos educandos, estimulá-los a avaliar constantemente os seus progressos e suas carências, ajudá-los a tomar consciência de como a aprendizagem se realiza. (p. 46)

Reconhece-se, assim, que o currículo opera via ferramentas pedagógicas que atuam como técnicas de produção dos sujeitos, tais como as lições, os conteúdos, os signos, as situações didáticas, os processos de avaliação, os espaços possíveis, os interditos, os dizeres admitidos, os dizeres silenciados. Essas ferramentas movimentam-se como um conjunto complexo de relações sociais e culturais permeadas pelas relações de poder-saber-ser fazendo operar a maquinaria da escola.

Jorge Larrosa (1999) aponta como uma das inércias no campo pedagógico a ocultação da própria pedagogia como uma operação constitutiva, isto é, como produtora de pessoas, e a crença arraigada de que as práticas educativas são meras 'mediadoras' onde se dispõem os 'recursos' para o desenvolvimento dos indivíduos. (p. 37)

Ou seja, a escola determina os referentes e os critérios de desenvolvimento dos sujeitos, disfarçando-se num vocabulário pedagógico que parece ter uma

relação do sujeito consigo mesmo: autoconhecimento, auto-estima, auto-controle, auto-confiança, autonomia, auto-regulação e auto-disciplina. (p. 38)

Trata-se de um vocabulário bem afinado com a gramática do discurso pedagógico do campo curricular da educação de jovens e adultos no Brasil, em particular na região discursiva de política educacional.

Em síntese, sendo o sujeito o resultado dos dispositivos que o constroem como tal, defendemos que o sujeito multicultural é construído historicamente no limiar entre a modernidade e a pós-modernidade. Na mesma formação discursiva pela interculturalidade (no campo curricular da EJA), há um discurso do cidadão da modernidade e, ao mesmo tempo, um discurso do cidadão multicultural identificado pela organização da sociedade civil, o que, ao nosso olhar, concede a esse discurso um caráter híbrido, se considerarmos que a sociedade civil é também identificada na organização dos Estados modernos.

\section{Processos de subjetivação do sujeito da educação de jovens e adultos na perspectiva intercultural: regra de normatização do sujeito da interculturalidade}

Segundo Larrosa (1999),

as práticas educativas são consideradas como um conjunto de dispositivos orienta- 
dos à produção dos sujeitos mediante certas tecnologias de classificação e divisão. (p. 52)

No texto do autor, está implícita a noção de que os processos de subjetivação dos indivíduos envolvem tecnologias de classificação e de divisão. Esse processo, no qual técnicas de classificar e técnicas de dividir produzem formas diversas de ser e de dizer, de andar, de relacionar-se, constitui, na verdade, procedimentos nos quais se revelam os efeitos de poder que normalizam as formas de ser dos indivíduos e dos grupos sociais e culturais. Essencialmente, eles funcionam como regras, como mecanismos de autorização/ desautorização das formas ditas adequadas de ser e de dizer sobre sua identidade cultural.

0 discurso pela interculturalidade, ao contrapor-se às formas homogeneizadoras, apresenta uma vontade de saber e problematiza experiências dominantes de currículos monoculturalistas, ao mesmo tempo em que produz subjetividades. Pressupõe-se que, se estamos a tratar de discursos educativos, precisamos encará-los como constituintes dos objetos dos quais falam ou cuidam, tal como nos alerta José Alberto Correia (1999) quando afirma:

Eles [os discursos educativos] são antes constitutivos deste objecto, na medida em que, na educação, a factualidade nunca tem uma existência autónoma relativamente ao campo onde se produzem as opiniões educativas; ou seja, a imbricação ontológica entre factos e opiniões em educação não permite um trabalho de purificação metodológica onde a factualidade se oponha à controvérsia das opiniões. (p. 81)

0 discurso curricular existe no interior da escola sob a função de "regular, disciplinar o indivíduo" (POPKEWITZ, 1994, p. 186). Entendido como um dispositivo de normalização de saberes/seres, de prática de sentido, de fixação de identidades sociais e culturais, o currículo incorpora ferramentas pedagógicas já mencionadas aqui (conteúdos, situações didáticas, processos de avaliação, espaços possíveis, interditados, dizeres admitidos, dizeres silenciados). Ele também incorpora um conjunto complexo de configurações sociais e culturais permeadas pelas relações de poder-saber-ser que definem a arquitetura do discurso em favor do respeito às diferenças culturais e sociais, ao mesmo tempo em que instauram formas singulares de dizer didaticamente sobre a diversidade cultural. Exemplo desse enquadramento é o formato prescritivo do discurso, tal como aparece no enunciado do currículo do MEC em relação aos objetivos didáticos do conteúdo diversidade cultural da sociedade brasileira:

- Reconhecer o caráter multiétnico e a diversidade cultural da sociedade brasileira, adotando perante tal pluralidade atitudes isentas de preconceitos.

- Reconhecer os povos indígenas como primeiros habitantes do Brasil e seus direitos à preservação da identidade cultural e ao território. [...]

- Conhecer traços culturais dos principais grupos étnicos africanos presentes no Brasil, valorizando-os enquanto elementos constitutivos do patrimônio cultural da sociedade brasileira. [...]

- Conhecer traços culturais de algumas nacionalidades que imigraram para o Brasil, valorizando-os enquanto elementos constitutivos do patrimônio cultural da sociedade brasileira. (RIBEIRO, 2001, p. 189)

É importante pontuar que a essa instância de delimitação (o currículo) está associada uma legislação específica: a Lei $n^{\circ}$ 9.394, de 1996, que estabelece as diretrizes e bases da educação nacional, e a Resolução CNE/CEB n ${ }^{\circ}$ 1 , de 5 de julho de 2000, que estabelece as diretrizes curriculares nacionais para a educação de jovens e adultos. Essa legislação educacional, por sua vez, está condicionada à lei maior do país, a Constituição da República Federativa do Brasil, de 1988, na qual, como resultado de 
lutas históricas, os povos indígenas e afrodescendentes viram ser instituído o respeito em relação à diversidade étnica e em relação à terra aos descendentes dos quilombos.

Por outro lado, ao nosso olhar, a interculturalidade é um discurso que reflete os embates ocorridos em outros domínios e também no conjunto interdiscursivo que lhe assegura as regularidades, fazendo com que o discurso pela interculturalidade seja multifacetado (gerado em diversos campos de saber), móvel (há uma redefınição permanente dos elementos que o compõem) e fundamentalmente problemático. Problemático pois funciona, em relação à questão da educação intercultural, como uma tensão, se entendermos que os processos de normalização são as funções por excelência do dispositivo educacional e que, tal como sustenta Foucault (1995), a normalização impede a diferenciação dos indivíduos, atuando, portanto, como um processo que impõe a homogeneidade. Esse sistema de normalização pode ser entendido como uma espécie de tensão no discurso pela interculturalidade, não apenas porque impõe a homogeneidade, o que já representa conflito no âmbito do discurso, mas também pelas tecnologias de governamento dos indivíduos que esse discurso está a produzir.

Dessas prescrições, podemos inferir que o discurso pela interculturalidade dáse em relações de poder imediatas, locais e interligadas umas às outras segundo uma lógica de estratégia global. E é por meio do poder inerente ao discurso que as regras são estabelecidas. Como diz Foucault (1994), "o poder atua pronunciando a regra, [...] por um ato de discurso que cria, justamente porque se articula, um estado de direito" (p. 86). Por seu turno, o discurso encontra-se associado a um ritual da palavra escrita, ritual este que determina, para os sujeitos que escrevem, papéis preestabelecidos que permitem sua existência, sua circulação e sua distribuição segundo regras próprias, isto é, regras que governam os diferentes elementos de afirmação e moldura da identidade do discurso pela interculturalidade no campo da EJA.

\section{Considerações finais}

Intentamos com este trabalho, a partir de uma aproximação ao pensamento póscolonialista e à arqueologia do discurso, contribuir para o debate sobre a relação entre discurso curricular e subjetividades em termos de melhor lidar com problemas que remetem à relação entre currículo e cultura, em particular no que se refere à problematização da vontade de poder da racionalidade eurocêntrica na produção de subjetividades nas escolas, aos efeitos de vontade de verdade da racionalidade ocidental e aos efeitos de vontade de verdade da racionalidade masculina ocidental.

Consideramos ser importante tanto uma aproximação à construção de uma pedagogia na perspectiva da interculturalidade, quanto uma problematização dessa vontade de verdade do saber/ser do sujeito coletivo/multicultural. Isso se justifica pelos riscos de estarmos a pedagogizar a diferença, isto é, de estarmos novamente a fazer embalagens bem iguais, bem quadradas, e, nelas, também colocarmos os sujeitos sociais e culturais; daí a necessidade de mantermos uma vigilância ética, estética e epistemológica em relação aos nossos próprios discursos.

Nesse sentido, defendemos que sejam considerados os seguintes princípios no debate curricular intercultural: i) a concepção de linguagem como sistema de nomeação e de produção dos objetos sobres os quais se fala; ii) os princípios da contingência e da historicidade radical na desnaturalização dos discursos; iii) a reflexão sobre uma teoria da reelaboração; iv) as relações de poder-saber-ser como indicativos da produtividade no campo educacional; v) o currículo como um campo da estética, da ética e da política; vi) as formas de regulação social e cultural implícitas nos discursos educacionais (VEIGA-NETO, 1998). 


\section{Referências}

BHABHA, Homi. 0 local da cultura. Belo Horizonte: Autêntica, 2000.

BRASIL, Ministério da Educação. Conselho Nacional de Educação. Parecer CNE/CEB n 11, de 10 de maio de 2000. Estabelece as diretrizes curriculares nacionais para a Educação de Jovens e Adultos. Diário Oficial da União, Brasília, DF, 9 jun. 2000. Seção 1e, p. 15.

CANEN, Ana. Multiculturalismo e formação docente: experiências narradas. In: REUNIÃO ANUAL DA ANPED: Diversidade e desigualdade: desafios para a educação na fronteira do século, 22., 1999, Caxambu. Anais... Rio de Janeiro: Mundo Virtual, 1999. CD-ROM.

CARVALHO, Rosângela Tenório. Interculturalidade objeto de saber no campo curricular da Educação de Jovens e Adultos. Educação em Revista, Belo Horizonte, v. 40, p. 115-150, 2004.

. Escola e diferença cultural: 0 debate da diferença cultural no campo do currículo da Educação Básica. In: SCOTT, Parry; LEWIS, Liane; QUADROS, Marion Teodósio de (Orgs.). Gênero, diversidade e desigualdade na educação: interpretações e reflexões para formação docente. Recife: Editora Universitária da UFPE, 2009. p. 41-63.

. Educação básica e políticas curriculares: o discurso da diferença cultural. Retratos da Escola, Brasília, v. 4, p. 271-283, 2010.

CASTRO-GÓMEZ, Santiago. Ciencias sociales, violencia epistémica y el problema de la invención del otro. In: LANDER, Edgardo. La colonialidad del saber: eurocentrismo y ciencias sociales. Perspectivas latinoamericanas. Buenos Aires: FLACSO, 2003. p. 145-162.

CEAAL. Plan Global CEAAL. México, D. F.: Impreso en Impresora Peña Santa, 2000.

CORAZZA, Sandra Mara. Planejamento de ensino como estratégia de política cultural. In: MOREIRA, Antonio Flavio B. (Org.). Currículo: questões atuais. Campinas: Papirus, 1997. p. 103-143. $\overline{\text { jul. } 2001 .}$

Na diversidade cultural, uma 'docência artística'. Pátio: revista pedagógica, Porto Alegre, ano V, n. 17, p. 27-31, maio/

CORDEIRO, Edmundo. Foucault e a existência do discurso. Cadernos do Noroeste, Braga, v. 8, n. 1, p. 179-186, 1995.

CORREIA, José Alberto. As ideologias educativas em Portugal nos últimos 25 anos. Revista Portuguesa de Educação, Braga, v. 12, n. 1, p. 81-110, 1999.

COSTA, Marisa Cristina Vorraber (Org.). 0 currículo nos limiares do contemporâneo. 3. ed. Rio de Janeiro: DP\&A, 2001.

Estudos culturais em educação. Porto Alegre: UFRGS, 2004.

DEACON, Roger; PARKER, Ben. Educação como sujeição e como recusa. In: SILVA, Tomaz Tadeu (Org.). 0 sujeito da educação: estudos foucaultianos. Petrópolis, RJ: Vozes, 1994. p. 97-110.

DIÁZ, Mário M. Pedagogia, discurso y Poder. In: DIAZ, Mário M.; MUÑOZ, José (Eds.). Pedagogia, discurso y poder. Bogotá: COPRODIC, 1990. p. 39-69.

FANON, Frantz. Pele negra, máscaras brancas. Porto: Paisagem, 1975.

FISCHER, Rosa Maria Bueno. Foucault e o desejável conhecimento do sujeito. Educação e Realidade, Porto Alegre, v. 24, n. 1, p. 39-60, 1999.

FOUCAULT, Michel. História da sexualidade I: a vontade de saber. Lisboa: Relógio D’Água Editores, 1994.

. A arqueologia do saber. Rio de Janeiro: Forense Universitária, 1995.

Vigiar e punir: nascimento da prisão. Petrópolis, RJ: Vozes, 1996. 
0 sujeito e o poder. Cadernos do Noroeste, Sociedade e Cultura 1, Série Sociologia, Braga, v. 13, n. 1, p. 349-370, 2000.

FOUCAULT, Michel. A escrita de si. In: . Ética, sexualidade, política. Rio de Janeiro: Forense Universitária, 2004. p. 144162. (Col. Ditos \& Escritos, v. 5)

FREIRE, Paulo. Educação como prática de liberdade. Rio de Janeiro: Paz e Terra, 1997.

GUARESCHI, Neusa. Ideologia e discurso. Educação e Realidade, Porto Alegre, v. 22, n. 2, p. 165-185, 1997.

HUSÉN, Torsten. Nuevo análisis de la sociedad del aprendizaje. Barcelona: Paidós/MEC, 1988.

LARROSA, Jorge. Tecnologias do eu e educação. In: SILVA, Tomaz Tadeu (Org.). 0 sujeito da educação: estudos foucaultianos. Petrópolis, RJ: Vozes, 1999. p. 35-86.

LEITE, Carlinda Maria Faustino. 0 currículo e o multiculturalismo no sistema educativo português. Lisboa: Fundação Calouste Gulbenkian; Fundação para Ciência e Tecnologia; Ministério da Ciência e Tecnologia, 2002.

MARSHALL, James. Governamentalidade e educação liberal. In: SILVA, Tomaz Tadeu (Org.). 0 sujeito da educação: estudos foucaultianos. Petrópolis, RJ: Vozes, 1994. p. 21-34.

MARTON, Scarlett. Foucault leitor de Nietzsche. In: RIBEIRO, Renato Janine (Org.). Recordar Foucault. São Paulo: Editora Brasiliense, 1985. p. 36-46.

MCLAREN, Peter. Pós-modernismo, pós-colonialismo e pedagogia. In: SILVA, Tomaz Tadeu (Org.). Teoria educacional crítica em tempos pós-modernos. Porto Alegre: Artes Médicas, 1993. p. 9-40.

MST. Caderno de Educação nº 3: alfabetização de jovens e adultos - como organizar. São Paulo: Gráfica e Editora Peres, 1996.

POPKEWITZ, Thomas S. História do currículo, regulação social e poder. In: SILVA, Tomaz Tadeu (Org.). 0 sujeito da educação: estudos foucaultianos. Petrópolis, RJ: Vozes, 1994. p. 173-210.

RIBEIRO, Vera Maria Masagão (Coord.). Educação para jovens e adultos: proposta curricular - $1^{\circ}$ segmento. São Paulo: Ação Educativa; Brasília: MEC, 2001.

SADER, Eder. Quando novos personagens entram em cena: experiências e lutas dos trabalhadores da Grande São Paulo 1970-1980. Rio de Janeiro: Paz e Terra, 1988.

SILVA, Tomaz Tadeu. Teorias do currículo: uma introdução crítica. Porto: Porto Editora, 2000.

STOER, Stephen R.; MAGALHÃES, António M. Novas cidadanias, reconfiguração do contrato social e educação, 2003. (texto policopiado)

UNESCO. Quinta Conferencia Internacional de Educación de Adultos (CONFINTEA V). Educación de Adultos y Desarrollo, p. 279-334, 1997.

VEIGA-NETO, Alfredo. Currículo e história: uma conexão radical. In: COSTA, Mariza Vorraber (Org.). 0 currículo nos limiares do contemporâneo. Rio de Janeiro: DP\&A, 1998. p. 93-104.

Recebido em: 14.11.2010

Aprovado em: 08.11.2011

Rosângela Tenório de Carvalho é professora do Centro de Educação da Universidade Federal de Pernambuco. 
